\title{
The dangers of libel and how to avoid them
}

\author{
David Parsons
}

In 1969 the $B M \mathcal{F}$ published a scientific paper written by four highly qualified members of the department of anaesthesia at Birmingham University. The paper set out the results of an investigation into a special technique called intermittent intravenous methohexitone. All four scientists and the British Medical Association (the publishers of the $B M 7$ ) were subsequently sued for libel by $\mathrm{Mr}$ Stanley DrummondJackson, a dental surgeon who was expressly associated in the paper with the technique in question. The resulting trial lasted for 38 days, at which point a settlement was reached on the basis that each side would pay its own costs. All parties must by that time have wished that they had never become embroiled in a legal process whose protracted course had gained them nothing but a wearisome sojourn in the Royal Courts of Justice and a hefty bill from their legal advisors.

\section{Who is at risk?}

Times now are no easier for those involved in medical publishing. Enormous and well publicised awards of damages have meant that the propensity of individuals and corporate bodies to invoke the laws of libel has, if anything, increased in the last two decades. Moreover, in the case of medical journals the number of individuals prepared to commit themselves to proceedings is not significantly diminished by the fact that legal aid is not available to those suing for libel. Many potential medical litigants can rely on the help of funding from their defence body.

The risk of libel proceedings is one faced not simply by the publishers and editor of a journal like the $B M F$, but also by its individual contributors. Any person who "participates" in a libellous publication is in law liable for it. Participation in this context includes the submission of the relevant material for publication. Moreover, liability is joint and several, which means that the amount of any award of damages or costs can potentially be executed in full against any one of the people liable.

So, what steps should be taken by an author to minimise his or her risk of being sued for libel? Inevitably there is some oversimplification, but the questions which any author or editor ought as a matter of practice to ask themselves in assessing whether or not a publication is likely to present a serious risk of libel can be distilled into five (see box).

\section{Is it defamatory?}

The possibility of a claim in libel arises only if the publication contains a defamatory statement. The test to be applied in considering whether something is defamatory has been defined several times. It has been said that the appropriate question is whether the allegation tends to lower the person concerned in the estimation of right thinking members of society. Another test is whether the allegation exposes its subject to hatred, ridicule, or contempt. Almost all the

\section{Questions an author should ask \\ Is it defamatory? \\ Could the words be understood to refer to a particular person or body? \\ Is the publication covered by privilege? \\ Can the allegation be proved to be true? \\ Is comment a fair expression of opinion based on fact?}

tests can be summarised by asking: Would people think worse of the person in question as a result of reading this?

The category of defamatory allegations obviously includes derogatory suggestions about someone's personal integrity-for example, suggestions that someone is a liar, involved in illegal activity, or bankrupt would all be potentially libellous. A statement is, however, also capable of being defamatory even if it does no more than contain an attack on a person's professional integrity or a criticism of the way he or she carries out a job. As Lord Pearson stated in a decision in the course of Mr Drummond-Jackson's proceedings, "In the case of a dentist it may be said: if he uses a bad technique, he is a bad dentist and a person needing dental treatment should not go to him." It has been held actionable to say that a medical practitioner was "not fit to treat a dog" and to associate him with a quack medicine in such a way as to suggest that he approved of it.

\section{IMPLICIT ATTACKS}

In this context authors and editors should be alive to the possibility of words bearing an implicit attack on character or professionalism which goes beyond what is expressly stated. It is no defence that a paper or article has been artfully drafted so that it does not expressly make a defamatory allegation against a person. It is enough if there is a defamatory hint or suggestion which the ordinary reader, perhaps reading between the lines, is likely to pick up. Frequently, for example, an ostensibly innocuous statement, such as "Mr A was not prepared to comment," can in a certain context acquire a sinister connotation-namely, that $\mathrm{Mr}$ A has something to hide. A further example of this type of implicit attack arises when rumours are reported. Unless it is very carefully worded, the report of a rumour conveys to the reader not simply that a rumour exists but also that there is some truth to it. In one well-known case Lord Hodson said, "If one repeats a rumour one adds one's own authority to it and implies that it is well-founded."

\section{INTENTIONS IRRELEVANT}

Also it is no defence that the author of the piece was not intending to say anything defamatory. The proper test is not what the author intended to say by the words published but how they would have been understood by the sort of people likely to read them. If an author
Inn, London WC1R 5EU David Parsons, barrister 


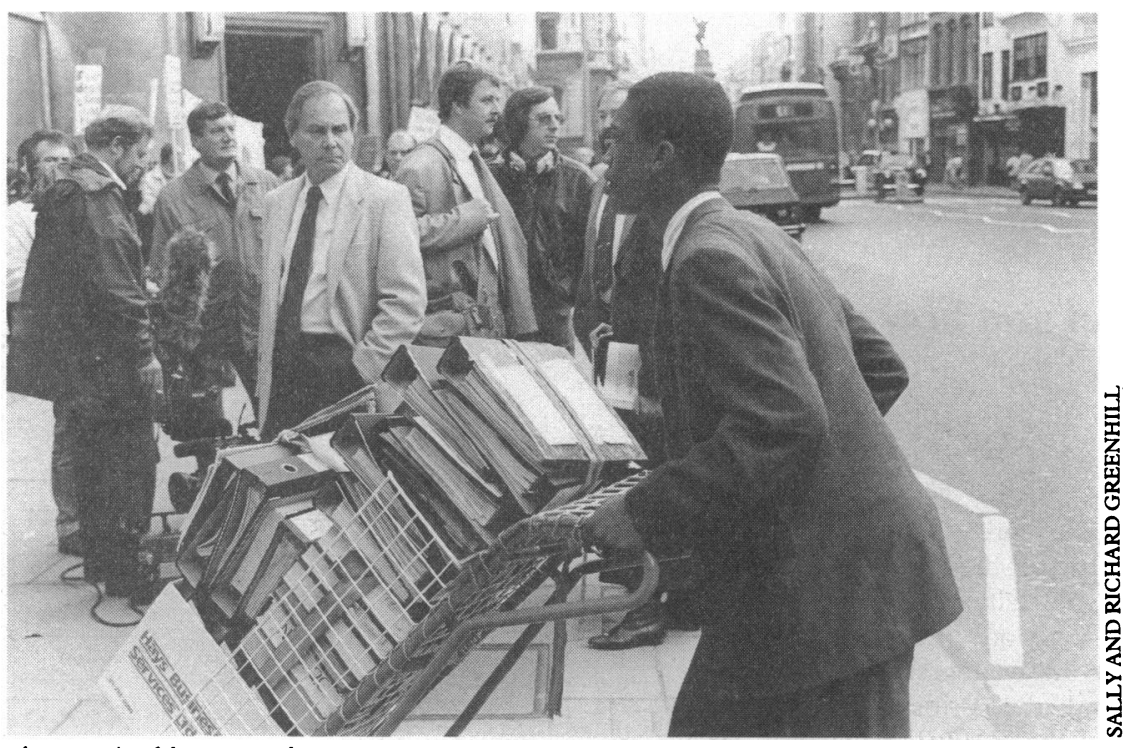

A mountain of documents, days in court, and a hefty bill-all from an inconsidered word or phrase

has allowed him or herself to be misinterpreted by right thinking people he or she must take the consequences.

\section{Reference to a living person}

The question: Could the words be understood to refer to a particular living person or corporate body? is relevant because authors can make defamatory allegations about dead people or large groups of people with impunity. Where they get into potential difficulty is where they attack a group that is sufficiently small that individuals in the group can legitimately say that the words would have been understood as referring to them. For example, it has been held that each member of a jury of 12 men could bring an action in respect of an article describing their verdict as "infamous."

Just as authors do not always escape liability by referring to groups of people, so they do not necessarily avoid trouble by resorting to anonymity. If a complainant can prove that somebody understood the allegation as being a reference to him or her, that is sufficient, even if he or she is not expressly named. The subject of an article can often be identified either from information contained in the piece or from extrinsic facts known to the reader. Thus, if a company was well known as the sole manufacturer of a certain piece of surgical equipment that company could bring proceedings in respect of an article criticising the dangerous design of the equipment, even if the make of the equipment was nowhere mentioned in the article.

\section{THE DANGERS OF CONTEXT}

Finally on the question of reference, it is often possible for a person named in an article to complain that some subsequent passage in which he or she is not mentioned is, in the context of the article as a whole, to be construed as referring to him or her. It follows that authors must be very careful to ensure that what they intend as no more than generalisations cannot be interpreted as being an attack on a person identified elsewhere in the article. For example, it would be potentially problematic to refer in one part of an article to some minor misconduct on the part of a named individual working in the NHS and in another part of the same article to state that the NHS is rife with fraud and grossly improper practice.

\section{Defences}

If the first two questions discussed above have been answered in the affirmative the author or editor faces a potential claim in libel because to establish such a claim, a complainant has to do no more than show that a defamatory statement has been published which refers to him or her.

The next step is then to consider whether or not there is some obvious defence to the claim. There are three substantive defences to a claim in libel: absolute and qualified privilege, justification, and fair comment (see box).

\section{Is the publication covered by privilege?}

The defence of privilege arises in circumstances where it is deemed that, for reasons of public policy, a person should be permitted to communicate free from the constraints of the laws of libel and slander. In certain situations the privilege is absolute; in others it is qualified by the requirement that the communication be made in good faith. The most well known examples of qualified privilege are fair and accurate reports of proceedings in the courts or in either the Houses of Parliament or parliamentary committees. The privilege also extends to fair and accurate reports of lesser tribunals, such as those of the General Medical Council or coroner's courts.

A fair and accurate report must give all the sides of the story. So, where a charge is reported, the verdict ought also to be reported or, if there has not yet been a verdict, it should be stated, if appropriate, that the accused denies the charge. It is important to maintain a balance.

Privilege also arises where there is a duty or interest in making the publication and the reader has a reciprocal duty or interest in receiving the publication. It has in the past been suggested that medical journals should have their own defence of qualified privilege. The argument in support of such a defence is that medical journals circulate almost exclusively within the medical profession and that within that circle it is more important that criticisms be made and investigated than that individuals' reputations be protected. Such a defence has not yet, however, found its way on to the statute books.

\section{Can the allegation be proved to be factually true?}

It is not enough that the writer or publisher is convinced or has been assured that the allegation is true. If there is a risk of legal proceedings the author must ensure that there is available admissible evidence of the truth of the allegation. If the source for the story is someone who will never give evidence about it in court - or who has a string of convictions for fraud so that he will never be believed-then, however accurate the story may in fact be, there is a real risk in publishing it. The requisite evidence will generally be direct first hand evidence of a witness who is prepared to testify in court. Hearsay accounts, such as a journalist's notes of an interview or a doctor's records, will rarely suffice.

In addition, the justification must be directed to the real sting of the libel. Thus, if an article states that many people have denounced a particular scheme as illegal, it will not be sufficient for the purposes of justification to establish that many people have denounced the scheme in that way; one would need to have further evidence to justify the inferential meaning -namely, that the scheme in question was illegal.

\section{Fair comment}

Although fair comment is a defence, it is important to remember that the comment has to be based on actual facts which are referred to in the paper or article: To the extent that the words are words of comment, can they be said to be a fair expression of opinion based 
on true facts? An author cannot, for example, simply assert that some person's conduct is scandalous. He or she must first set out and explain, or at least allude to, the conduct in question (which must be true) and only then is it permissible to give a comment on it. For example, to state that a surgeon was guilty of a gutless abdication of his responsibilities would not be defensible as fair comment unless the author also made clear the basis for this comment-for example, that the surgeon had resigned on the ground that he objected to the introduction of new pay codes. The defence of fair comment would also not succeed in this instance if in fact the basis for the comment turned out to be incorrect and the surgeon proved that he had, for example, retired on grounds of ill health.

It is important for authors to ensure that what they are saying is in fact comment and not simply an allegation dressed up to look like an expression of opinion. If the allegation, although expressed in the language of comment, is likely to be read as an assertion of fact-for example, "Dr A would appear to have broken every rule in the book"-the defence of fair comment will not apply and the appropriate defence to consider is that of justification.
The boundaries of fair comment are wide and, providing authors are commenting on true facts, they are entitled to express their honest opinion, however forthright. Nevertheless, caution is advisable where an author is speculating about an individual's state of mind. For example, it is dangerous to say that someone's conduct is plainly vindictive or that a person is evidently operating for reasons of personal profit. It will always be hard to convince a court that such inferences about an individual's personal motivations are fairly to be drawn from the surrounding facts of the case.

\section{MALICE}

Finally, the defence of fair comment, as well as the defence of qualified privilege, can be defeated if it is established that the publication was made with malice. Malice in this context includes not simply spite but also the existence of an ulterior motive. A case of malice can frequently be built on the fact that the writer of the piece in question has some vested interest in its subject matter. If the author of a piece is a person who might well be regarded as someone with an axe to grind great caution should be exercised.

\section{Medical Education}

\section{Trends in health care and their effects on medical education}

\section{Stella Lowry}

This is the eighth in a series of articles examining the problems in medical education and their possible solutions
British Medical Journal, London WC1H 9JR Stella Lowry, assistant editor

$B M f 1993 ; 306: 255-8$
The General Medical Council has recognised for decades that there are problems in medical education, but little real reform has happened. In recent years, however, there have been dramatic changes in the provision of health care services which are having knock on effects on medical education. Here I shall discuss some of the strongest of these forces in more detail and examine ways in which they can be turned to advantage in shaping medical education.

\section{Specialisation}

The GMC believes that increasing specialisation within medicine and the development of postgraduate medical education are among the biggest influences on the way we train doctors. ${ }^{1}$ Doctors cannot now make a career in any branch of medicine in Britain without taking part in postgraduate medical education. Each specialty is controlled by a royal college or faculty that dictates the required specialist training programme and sets the necessary standards. As a result the undergraduate medical course no longer needs to provide so much detailed factual knowledge about individual specialties. A newly qualified doctor must be able to function as a preregistration house officer and have the skills to take full advantage of postgraduate education. ${ }^{2}$ Realistically, the detailed factual knowledge needed to begin specialist training in most disciplines could probably be learnt by a motivated senior house officer in a matter of a few weeks at the start of specialist training.

By removing much of the factual load from the undergraduate curriculum we can clear space for topics like communication skills, teamwork, audit and management, appreciation of scientific method, ethics, information technology, etc. All of these are relevant to modern medical practice and provide the student with the skills needed to continue learning beyond the sheltered confines of the medical school, and their importance is emphasised in the contents suggested by

\begin{tabular}{l} 
Box 1 \\
Contents of core curriculum proposed by GMC \\
- Clinical method, practical skills, and patient care \\
- Communication skills \\
- Normal structure and function: human biology \\
- Abnormal structure and function: human disease \\
- People in society \\
- The public health \\
- Disability and rehabilitation \\
- Finding out: research and experiment \\
\hline
\end{tabular}

the GMC for the proposed core medical curriculum ${ }^{1}$ (box 1).

\section{Changing role of hospitals}

Huge changes in the politics and philosophy of health care have occurred in recent years, which are having knock on effects in medical education (N Bosanquet, paper delivered at conference on developing medical education, University of London, 26-27 June 1991). ${ }^{3-5}$ Much more emphasis is now put on epidemiology, the health of populations, health promotion, and preventive medicine. Maintaining health is as important as treating disease. Demographic changes mean that medicine of old age is becoming increasingly important.

Much of our health care is now provided entirely in the community. General practitioners have a formal postgraduate education system of their own, and the roles of other members of the primary care team have developed to provide a huge range of specialist professional services. These trends have been accompanied by changes in the way our hospitals function. For various reasons, including the opportunities offered by 